wall, and large gut. All the tissues which contained squamous epithelium stained readily with both pemphigus and practolol sera, but no significant staining was seen in any of the other tissues.

Ability of Antibodies to Stick to Isolated Epidermal Cells.The staining pattern obtained when trypsinized, aggregated epidermal cells were treated with pemphigus sera is shown in fig. 2. About one-third of the epidermal cells took up the antibody, which appeared localized in aggregates mainly around the periphery of the cells (Brigden et al., 1975). A similar cell preparation treated with 11 sera from group 1 did not stain.

\section{Discussion}

We have found an antibody which sticks to the intercellular region of squamous epithelial tissue and is associated with a distinct type of conjunctival damage induced by practolol, though it is too early to be dogmatic about the association. The fact that the intercellular region of the epidermis is the antibody's target in vitro inevitably raises the question of its relation to the antibody found in pemphigus even though the immunological specificity of both antibodies is unknown.

The pemphigus antibody will bind to trypsinized epidermal cells whereas the practolol antibody will not, which might suggest that the two antibodies bind to different determinants in the tissues. Unfortunately, there is no evidence to support the accepted concept that pemphigus antibodies react with skin antigens, and either antibody might behave as an IgG cytophilic antibody and attach itself to Fc receptors in target tissues. Under these circumstances it would be reasonable to argue that such an antibody might have specificity for antigens other than those of skin tissue, such as drug determinants.

The significance of the intercellular antibody in the sera of patients taking practolol is unknown, but a preliminary investigation in which serial serum samples from practolol-treated patients were tested for antibody suggests that the titre may reflect the degree of eye-associated tissue damage. If this is so then the antibody titre might be valuable in monitoring treatment or even predicting likely damage. We cannot, however, postulate any role for the antibody in the production of tissue damage until its specificity has been determined by further investigations.

We thank Mr. P. Wright, Dr. F. J. Zacharias, Dr. J. Cosh, Dr. P. Hickling, and Dr. L. Holt for supplying the sera.

\section{References}

Brigden, W. D., and Amos, H. E. (1975) Submitted for publication

Felix, R. H., Ive, F. A., and Dahl, M. G. C. (1974). British Medical fournal, 4,321 .

Raftery, E. B., and Denman, A. M. (1973). British Medical fournal, 2, 452

Wiseman, R. A. (1971). Postgraduate Medical fournal, 47, Suppl. 2. p. 68 Wright, P. (1974). British Medical fournal, 2, 560 .

Wright, P. (1975). British Medical fournal, 1. 600.

\title{
Myasthenia Gravis associated with Penicillamine Treatment for Rheumatoid Arthritis
}

\author{
R. C. BUCKNALL, \\ A. ST. J. DIXON, \\ E. N. GLICK, \\ J. WOODLAND, \\ D. W. ZUTSHI
}

British Medical fournal, 1975, 1, 600-602

\begin{abstract}
Summary
Four patients with rheumatoid arthritis (R.A.) developed myasthenia gravis after taking penicillamine. In one patient withdrawal of the drug was followed by spontaneous remission of the myasthenia, and in two the dose of anticholinesterase was subsequently reduced. In the fourth patient continuing penicillamine treatment was associated with increasingly severe myasthenic features, but on withdrawal of the drug these resolved. As myasthenia gravis rarely complicates R.A. its onset in these patients shortly after the start of penicillamine treatment suggested that penicillamine may have precipitated this condition.
\end{abstract}

\section{Introduction}

At a recent international symposium Miehlke (1974), Bröll (1974), and Ott (1974) each reported that they had observed

Royal National Hospital for Rheumatic Diseases, Bath BA1 1RL

R. C. BUCKNALL, M.B., M.R.C.P., Medical Registrar

A. St. J. DIXON, M.D., F.R.C.P., Consultant Physician

Chase Farm Hospital, Enfield, Middlesex

E. N. GLICK, M.B., M.R.C.P., Consultant Rheumatologist

Department of Rheumatology, Prince of Wales's Hospital, London N. 15

J. WOODLAND, M.B., M.R.C.P., Senior Registrar

D. W. ZUTSHI, M.B., M.R.C.P., Consultant Physician muscle weakness and myasthenic signs in a total of four patients with rheumatoid arthritis (R.A.) who had been treated with penicillamine. Camus (1974) described similar features in a patient with systemic lupus erythematosus being treated with penicillamine. We report here four patients with active classical R.A. (American Rheumatism Association criteria (Ropes et al., 1959)) who developed myasthenia gravis after taking penicillamine for at least four months.

\section{Case 1}

A 49-year-old woman with a 12-year history of R.A. had been treated with corticosteroids and sodium aurothiomalate but benefit was not sustained. Penicillamine treatment was started, the initial dose of 250 $\mathrm{mg} /$ day being increased by $250 \mathrm{mg}$ each week to $1 \mathrm{~g} /$ day. Eight months after beginning penicillamine treatment she developed diplopia, dysphagia, dysarthria, and difficulty in mastication. Later she complained of generalized weakness, inability to sit up from the lying position unaided, and a drooping of her eyelids which became worse towards the evening. For about six months she had been unable to make tears but did not complain of a dry mouth. She was admitted to hospital where her disabilities were confirmed and proteinuria detected.

Investigations.-Haemoglobin was $10.0 \mathrm{~g} / \mathrm{dl}$; she was positive for rheumatoid factor (latex test); Rose-Waaler test showed a titre of 1/128; proteinuria was $1.3 \mathrm{~g} / 24 \mathrm{~h}$; thyroid function was normal; antinuclear factor was present but organ-specific antibodies were absent; chest radiography showed no evidence of a thymoma; and the Schirmer test showed no tear production. A therapeutic test with $10 \mathrm{mg}$ of edrophonium chloride intravenously gave an equivocal result, but $2 \mathrm{mg}$ of neostigmine intramuscularly produced a dramatic improvement in all her signs within five minutes which lasted for 30 minutes. She was then able to sit up unaided, ptosis was abolished, maintenance of upward gaze was improved from 30 seconds to two 
minutes, and her vital capacity increased from 2.4 to $2 \cdot 85$. She was able to chew her food at supper that evening.

Penicillamine was withdrawn on admission to hospital, but anticholinesterase therapy was not begun and after two weeks the patient began to recover spontaneously from her myasthenia. Two months later there was an appreciable subjective improvement, and she could sit up unaided and maintain an upward gaze for at least three minutes.

\section{Case 2}

A 40-year-old man who had R.A. for six years had been treated with sodium aurothiomalate but developed a rash. Hydroxychloroquine produced a remission but after three years he again relapsed. Penicillamine $250 \mathrm{mg} /$ day was begun, and the dose was increased by 250-mg increments each week to $1 \mathrm{~g} /$ day. After one month his arthritis was still active and prednisolone $10 \mathrm{mg} /$ day was added, the dose being reduced to $7.5 \mathrm{mg}$ after two months. Five months after first taking penicillamine he developed drooping of the left eyelid, most marked in the evening, diplopia, and weakness of the arms such that he was unable to continue painting the ceiling. Myasthenia gravis was diagnosed by edrophonium chloride therapeutic tests.

Investigations.-Haemoglobin was $14.8 \mathrm{~g} / \mathrm{dl}$; he was positive for rheumatoid factor; thyroid function was normal; antinuclear factor was present but organ-specific antibodies were absent; chest $x$-ray films and a thoracic inlet tomogram showed no evidence of a thymoma; and the Schirmer tear test was normal. Because his arthritis had responded well and there was no evidence of other toxicity penicillamine was continued. He was started on pyridostigmine hydrochloride $180 \mathrm{mg} /$ day, and initially his myasthenia was well controlled. Two months later, however, diplopia and increasing weakness recurred such that he was unable to maintain an upward gaze for more than 45 seconds or hold his arms horizontally for more than 15 seconds. Penicillamine was discontinued and the dose of pyridostigmine increased to $360 \mathrm{mg} / \mathrm{day}$, and within two weeks these features began to remit and six weeks after withdrawal of penicillamine he was well except for mild diplopia in the evening. The dose of pyridostigmine was gradually reduced and eventually discontinued.

\section{Case 3}

A 56-year-old woman had had R.A. for two years. Because of deterioration she was treated with penicillamine $250 \mathrm{mg} / \mathrm{day}$, the dose being increased to $500 \mathrm{mg} /$ day after one month. She then noticed fatigue, which became worse in the evening. The daily dose of penicillamine was increased by $250 \mathrm{mg}$ each month to $1 \mathrm{~g}$ /day. Four months after starting treatment she developed a left ptosis and was referred for a neurological opinion. By that time her complaints included fatigue, drooping of both eyelids in the evening, and weakness of the arms.

Investigations.-Full blood picture was normal; latex test for rheumatoid factor positive; a Schirmer test showed impaired tear secretion; thyroid function was normal; test for antinuclear factor was weakly positive; organ specific antibodies were absent; chest $x$ ray films and thoracic inlet tomogram showed no evidence of a thymoma; and an electromyogram was normal. An edrophonium hydrochloride test produced a rapid improvement in the sensation of fatigue and the ptosis. With pyridostigmine $240 \mathrm{mg}$ /day improvement was sustained. Penicillamine was discontinued. It was restarted a month later in a dose of $250 \mathrm{mg}$ /day in addition to the pyridostigmine. There was no recurrence of the symptoms or signs of myasthenia, but after a further month penicillamine had to be discontinued because of indigestion. The dose of pyridostigmine was subsequently reduced to $120 \mathrm{mg} /$ day.

\section{Case 4}

A 29-year-old woman had had R.A. for one year. She responded initially to sodium aurothiomalate but this, and subsequently chloroquine, were discontinued because of a rash. Penicillamine was substituted in a dose of $250 \mathrm{mg} /$ day, increased by gradual increments over two months to $1250 \mathrm{mg} /$ day and later reduced to $750 \mathrm{mg} /$ day after a further three months. Her arthritis improved but nine months after starting penicillamine she complained of blurring of vision and during the next month developed diplopia, dysarthria, dysphagia, and marked fatigue. Myasthenia gravis was diagnosed and penicillamine discontinued.

Investigations. - She was positive for rheumatoid factor, weakly positive for antinuclear factor, and negative for antibodies to striated muscle and organ-specific antibodies; chest radiography and thoracic inlet tomography showed no evidence of a thymoma; and an electromyogram was normal. She improved greatly after an edrophonium chloride test and was started on pyridostigmine $360 \mathrm{mg} /$ day. At first the dose had to be increased to $600 \mathrm{mg} /$ day, but she gradually improved and her requirements became less. When last seen she was taking $240 \mathrm{mg} /$ day.

\section{Discussion}

Myasthenia gravis has been described in association with various autoimmune diseases including systemic lupus erythematosus and hyperthyroidism. In reviewing 508 patients with myasthenia Simpson (1966) found 20 cases (3.9\%) with R.A., and Downes et al. (1966) found five patients (6.7\%) with R.A. and one with Sjögren's syndrome among 74 patients with myasthenia gravis. About $1-4 \%$ of Britain's population are estimated to have R.A. Oosterhuis and De Haas (1968) studied 60 patients in Amsterdam who had had myasthenia gravis for an average of 10.5 years and found five women with R.A. (8.3\%), a frequency double that expected from the 1962 Netherlands Survey of Rheumatic Diseases (Graaf, 1962). Nevertheless, of the total number of patients with myasthenia gravis known to them ( 96 women and 46 men) only seven, all women, had R.A. $(4.9 \%)$. In evaluating such findings it is necessary to remember the "two diseases fallacy." Patients with two diseases are more than twice as likely to be referred to hospital and when in hospital to be noticed and written up than patients with one disease. In a later study Oosterhuis and De Haas (1969) failed to show an increased frequency of latent myasthenia gravis in patients with R.A. as determined by a curare sensitivity test.

We have been unable to find reliable statistics on the incidence of myasthenia gravis in an unselected series of patients with R.A., but the impression from the three centres participating in our study is that this complication is rare. Therefore, the occurrence of myasthenia gravis in four patients shortly after starting penicillamine treatment for R.A. suggests more than a coincidence. Antibiotic-induced neuromuscular blockade has been described (Wright and McQuillan, 1971), and polymyxin, colomycin, neomycin, viomycin, streptomycin, kanamycin, and bacitracin have all been implicated but not penicillin.

In case 1 withdrawal of penicillamine resulted two weeks later in spontaneous remission of myasthenia, and anticholinesterase drugs were not needed. In the other three patients the requirement for pyridostigmine diminished, and in case 2 the drug was discontinued. Spontaneous remissions lasting more than a month normally occur in fewer than half the patients with myasthenia gravis (Simpson, 1974). In case 3 fatigue developed after only one month of treatment with penicillamine $250 \mathrm{mg} /$ day, but all patients had been on penicillamine for at least four months and received doses of at least $1 \mathrm{~g} /$ day before the full picture of myasthenia gravis developed.

Penicillamine will probably be used more often in the treatment of R.A. Three British multicentre controlled clinical trials have shown that penicillamine $1200 \mathrm{mg}$ /day is superior to placebo in the treatment of severe R.A. (Multicentre Trial Group, 1973); that $600 \mathrm{mg} /$ day is as effective as $1200 \mathrm{mg} /$ day when added to the regimen in both early and late R.A. (Davies et al., 1974); that both doses are superior to placebo; and that penicillamine is as effective as sodium aurothiomalate as an addition to the treatment of R.A. and complications leading to withdrawal are less common with penicillamine (Huskisson et al., 1974). Nevertheless, penicillamine is associated with such potentially serious toxic effects as thrombocytopenia and the nephrotic syndrome. Furthermore, patients with R.A., though treated with lower doses of penicillamine than those with Wilson's disease, more often develop these toxic effects (Lyle, 1974). This suggests that patients with R.A. may be particularly susceptible to toxic complications from penicillamine. Two of our patients (cases 1 and 3) had features suggestive of Sjögren's syndrome, in which drug sensitivity reactions are very common (Bloch et al., 1965). The patient in case 1 developed definite proteinuria while on penicillamine, which was probably due to 
a penicillamine-induced immune complex nephropathy (Tribe et al., 1974).

The mode action of penicillamine in R.A. is unknown. Thymus-derived lymphocytes are known to play an important part in the pathogenesis of autoimmune diseases, including R.A. In view of the finding of pathological changes in the thymus in $70-80 \%$ of patients with myasthenia gravis the effect of penicillamine in apparently precipitating myasthenia gravis in R.A. may therefore be of more than anecdotal interest.

We thank Dr. J. A. Cosh, consultant physician, Royal National Hospital for Rheumatic Diseases, Bath, for permission to publish details of case 1 ; Dr. G. S. Wakefield, consultant neurologist, Royal United Hospital, Bath, and Dr. G. D. Walker, general practitioner, for helpful information regarding case 2; Dr. K. J. Zilkha, consultant neurologist, National Hospital for Nervous Diseases, Queen Square, London, for helpful information and advice regarding case 3; and Dr. J. A. S. Davis, registrar in neurology at Chase Farm Hospital, Enfield, for his advice with case 4.

\section{ADDENDUM}

In case 3 pyridostigmine was subsequently withdrawn without any recurrence of myasthenic symptoms.

\section{References}

Bloch, K. J., et al. (1965). Medicine, 44, 187.

Bröll, H. (1974). Penicillamine: An International Symposium. Royal Society of Medicine. In preparation.

Camus, J. P. (1974). Penicillamine: An International Symposium, Royal Society of Medicine. In preparation.

Society of Medicine. In prepara:
Davies, J., et al. (1974). In Press.

Downes, J. M., Greenwood, B. M., and Wray, S. H. (1966). Quarterly Downes, J. M., Greenwood, B.

Fournal of Medicine, 35, 85.
Graaff, $\mathrm{R}$ de (1962) De Rheumatoide Arthritis in Nederland. Thesis, Leiden.

Huskisson, E. C., et al. (1974). Annals of Rheumatic Diseases, 33, 532

Lyle, W. H. (1974). Personal communication.

Miehlke, K. (1974). Penicillamine: An International Symposium. Royal Society of Medicine. In preparation.

Multicentre Trial Group (1973). Lancet, 1, 275.

Oosterhuis, H. J. G. H., and de Haas, W. H. D. (1968). Acta Neurologica Scandinavica, 44, 219.

Oosterhuis, H. J. G. H., and de Haas, W. H. D. (1969). Acta Rheuma-

tologica Scandinavica, $15,54$.
Ott, V. R. (1974). Penicillamine: An International Symposium. Royal Society of Medicine. In preparation.

Ropes, M. W., et al. (1959). Annals of the Rheumatic Diseases, 18, 49.

Simpson, J. A. (1966). Annals of the New York Academy of Sciences, 135 506.

Simpson, J. A. (1974). Disorders of Voluntary Muscle, ed. J. N. Walton, p. 654. London, Churchill Livingstone.

Tribe, C. R., Mackenzie, J. C., and Bacon, P. A. (1974). Penicillamine: An International Symposium. Royal Society of Medicine. In preparation Wright, E. A., and McQuillen, M. P. (1971). Annals of the New York Academy of Sciences, 183, 358.

\title{
Changes in Haemoglobin Binding Curve and Oxygen Transport in Chronic Hypoxic Lung Disease
}

\author{
D. C. FLENLEY， L. J. FAIRWEATHER， N. J. COOKE， B. J. KIRBY
}

British Medical fournal, 1975, 1, 602-604

\section{Summary}

Direct measurements of the factors determining blood oxygen transport in 10 patients with chronic hypoxic respiratory failure led to the conclusion that wide differences in the position of their oxygen binding curves, due to spontaneous differences in red-cell 2, 3-diphosphoglycerate, had little effect on oxygen delivery to the tissues, as assessed by the mixed venous oxygen tension when they were breathing air. This result arises from the shape of the oxygen binding curve. A drug which could shift the curve to the right would help tissue oxygenation in cardiogenic and other forms of shock, when a low cardiac output can not be improved though arterial blood can be well oxygenated.

\section{Introduction}

The discovery that variations in red-cell concentrations of 2, 3-diphosphoglycerate (2,3-DPG) could alter the affinity of haemoglobin for oxygen (Benesch and Benesch, 1967; Chanutin and Curnish, 1967) has led to intensive study of the binding of ligands to the haemoglobin molecule (Kilmartin and RossiBernardi, 1973). Nevertheless, less attention has been paid to the effects of variations in $2,3-D P G$ concentrations on oxygen

University Department of Medicine, Royal Infirmary, Edinburgh EH3 9YW

D. C. FLENLEY, PH.D., F.R.C.P., Reader in Medicine

L. J. FAIRWEA THER, B.SC., PH.D., Faculty of Medicine Research Scholar N. J. COOKE, M.B., M.R.C.P., Research Fellow (Present appointment: Senio N.J. COOKE, M.B., M.R.C.P., Research Fell

B. J. KIRBY, M.B., M.R.c.P., Lecturer (Present appointment: Senior B. J. KIRBY, M.B., M.R.C.P., Lecturer (Present app
Lecturer, Exeter Postgraduate Medical Centre, Exeter) transport in vivo, particularly in patients with hypoxaemia resulting from chronic lung disease. Transport of oxygen by the blood depends on the concentration of haemoglobin, the arterial oxygen tension $\left(\mathrm{PaO}_{2}\right)$, arterial $\mathrm{pH}$, and the cardiac output in addition to the oxygen binding curve. The position of this curve can be described by the oxygen tension necessary to obtain $50 \%$ full saturation $\left(P_{50}\right)$. We have measured all these variables in 10 hypoxaemic patients during right heart catherization to assess the effects of their different 2, 3-DPG levels on oxygen transport.

\section{Patients and Methods}

We studied 10 patients aged from 43 to 70 years, who were in a stable state of chronic hypoxaemia (mean $\mathrm{PaO}_{2}$ ( \pm S.D.) $6.4 \pm 1.03 \mathrm{kPa}$ $(48.1 \pm 7.7 \mathrm{~mm} \mathrm{Hg})$ ), with different levels of chronic $\mathrm{Co}_{2}$ retention $\left(\mathbf{P a C O}_{2} 7.3 \pm 1.6 \mathrm{kPa}(54.9 \pm 11.9 \mathrm{~mm} \mathrm{Hg})\right)$. All had irreversible airways obstruction $\left(\mathrm{FEV}_{1} 0.49 \pm 0.21 \mathrm{l}, \mathrm{FEV} \% 33 \cdot 7 \pm 11.0 \%\right)$ and hyperinflation of the lungs (residual volume $66 \cdot 5 \pm 10 \cdot 6 \%$ of total lung capacity). This confirmed the clinical diagnosis of cor pulmonale (pulmonary arterial mean pressure $4.8 \pm 1.5 \mathrm{kPa}(35.8 \pm 11.5 \mathrm{~mm} \mathrm{Hg})$ ) resulting from chronic bronchitis and emphysema, with different degrees of secondary polycythaemia (red cell mass $51 \cdot 4 \pm 19.5 \mathrm{ml} / \mathrm{kg}$ ). Right heart catherization and the other measurements were part of their assessment for long-term domiciliary oxygen therapy, and al patients gave informed consent to the procedures after the study had been approved by the local ethical committee.

When the patients were resting supine and breathing air simultaneous blood samples were taken from catheters in the brachial and pulmonary arteries, and oxygen uptake, by collection and analysis of expired gas, and cardiac output (green dye dilution) were measured. Blood gas tensions and pH were measured by IL 113 electrodes calibrated with tonometered blood (Flenley et al., 1967); oxygen capacity by spectrophotometry (King and Wooton, 1956) calibrated against the method of Van Slyke and Neill (1924); $P_{50}$ by a modification of the mixing technique (Edwards and Martin, 1956); red-cell mass by ${ }^{51} \mathrm{Cr}$ dilution; and 2,3-DPG by a modification of Krimsky's (1963) enzymatic assay. Details of these methods and their precision are given by Fairweather et al. (1974). 